\title{
Penerapan Algoritma Coupled Linear Congurential Generator (CLCG) pada Algoritma Kriptografi One Time Pad (OTP) dalam Proses Mengamankan Pesan
}

\author{
Deny Nugroho Triwibowo, Dony Ariyus* \\ Magister Teknik Informartika, Universitas Amikom Yogyakarta, Sleman, Indonesia \\ Email: ${ }^{1}$ deny.15@students.amikom.ac.id, ${ }^{2, *}$ dony.a@ amikom.ac.id \\ Email Penulis Korespondensi: dony.a@ amikom.ac.id
}

\begin{abstract}
Abstrak-Pesan merupakan suatu gagasan, perasaan, atau pemikiran seseorang yang isinya bisa berupa ilmu pengetahuan, hiburan, informasi, nasihat, atau propaganda. Saat ini dengan perkembangan teknologi yang sangat maju seseorang dapat bertukar pesan dengan begitu mudah dan cepat tanpa ada batasan jarak dan waktu. Namun, dengan semakin mudahnya bertukar pesan ada saja masalah yang dapat terjadi, salah satunya pesan yang ingin dikirim membuka peluang bagi orang-orang yang yang ingin mencuri data dan informasi dari pesan tersebut untuk menggunakannya sebagai tindak kejahatan dan tentunya akan merugikan pihak tertentu. Maka dari itu, digunakan teknik mengamankan pesan dengan menggunakan algoritma OTP dan pembangkit bilangan acak CLCG agar pesan yang dikirim tingkat keamanannya dapat dijamin. Hasil dari penggabungan algoritma OTP dan CLCG dalam proses enkripsi dan dekripsi didapatkan pembangkit kunci acak tidak terjadi perulangan kunci yang sama dengan karakter yang sama yang saling berdekatan pada pesan. Penggunaan tabel periodik dalam proses enkripsi juga menambah kesulitan untuk memecahkan pesan karena satu karakter plaintext digantikan dengan banyak karakter pada ciphertext.
\end{abstract}

Kata Kunci: Pesan, Kriptografi, One Time Pad (OTP), Coupled Linear Congruential Generator (CLCG), Tabel Periodik

Abstract-Message is an idea, feeling, or thought of someone whose contents can be in the form of science, entertainment, information, advice, or propaganda. Nowadays, with the development of very advanced technology, one can exchange messages so easily and quickly without any limitations on distance and time. However, with the ease of exchanging messages there are problems that can occur, one of which is the message you want to send opens opportunities for people who want to steal data and information from the message to use it as a crime and will certainly harm certain parties. Therefore, the technique of securing messages is used by using the OTP algorithm and the CLCG random number generator so that messages sent to the security level can be guaranteed. The results of the merging of the OTP and CLCG algorithms in the encryption and decryption process found random key generator does not occur the same key loop with the same characters adjacent to the message. The use of periodic tables in the encryption process also increases the difficulty of deciphering messages because one plaintext character is replaced by many characters in the ciphertext.

Keywords: Message, Cryptographi, One Time Pad (OTP), Coupled Linear Congruential Generator (CLCG), Periodic Tables

\section{PENDAHULUAN}

Pesan merupakan suatu gagasan, perasaan, atau pemikiran yang akan di-enkripsi oleh si pengirim dan di-dekripsi oleh penerima ketika ingin saling bertukar pesan [1]. Pesan yang akan dikirimkan dan diterima isinya bisa berupa ilmu pengetahuan, hiburan, informasi, nasihat atau propaganda yang pada dasarnya bersifat konkret atau abstrak. Di mana pembuatan pesan adalah hasil dari pengalaman yang pernah dilakukan atau untuk memberitahukan kejadian yang akan datang kepada seseorang [2]. Sebuah pesan dapat disampaikan secara lisan atau tulisan dengan cara tatap muka secara langsung atau melalui media komunikasi yang saat ini sudah begitu banyak aplikasi yang dibuat.

Aplikasi media komunikasi saat ini adalah perwujudan dari perkembangan teknologi yang makin hari semakin meningkat. Sehingga membuat seseorang dengan mudahnya bertukar informasi tanpa ada batasan jarak dan waktu. Namun, keamanan yang merupakan masalah utama yang terdapat dalam jaringan yang bebas berkaitan dengan pertukaran informasi dari pengirim ke penerima begitupun sebaliknya [3], hal ini akan membuka peluang bagi orang-orang yang yang ingin mencuri data dan informasi dari pesan tersebut untuk menggunakannya sebagai tindak kejahatan dan tentunya akan merugikan pihak tertentu [4]. Untuk itu dibutuhkan teknik dalam mengamankan suatu pesan, khususnya pesan yang di dalamnya terdapat informasi yang sifatnya penting atau rahasia dengan melakukan enkripsi sebelum dikirim ke tujuan, maka tingkat keamanan informasi dari pesan tersebut dapat dijamin.

Ada dua teknik yang telah populer dan banyak digunakan dalam proses keamanan pesan, yaitu, steganografi dan kriptografi [5]. Steganografi adalah teknik menyembunyikan pesan pada suatu objek untuk mengelabui indra penglihatan manusia [6]. Sedangkan kriptografi adalah teknik untuk mengubah bentuk pesan menjadi bentuk lain yang memiliki arti berbeda dengan pesan itu sendiri, bahkan memungkin membuatnya seperti file yang rusak, sehingga sulit dibaca atau dimengerti oleh pihak lain [7] [8] [9]. Teknik kriptografi merupakan teknik yang dapat digunakan untuk mengenkripsi naskah asli (plaintext) yang diacak menggunakan suatu kunci enkripsi menjadi naskah acak yang Ada begitu banyak metode yang digunakan dalam proses mengamankan pesan, salah satunya metode OTP (One Time Pad). One Time Pad sendiri bergantung pada kunci acak yang digunakan. Semakin tinggi jumlah kunci acak yang digunakan dan tidak menggunakannya kembali, maka keamanan chipertext dari One Time $\mathrm{Pad}$ akan semakin tinggi yang membuatnya sangat aman dan sulit dipecahkan [10]. Penggunaan pembangkit 
bilangan acak untuk mendapatkan kebutuhan kunci yang ingin digunakan pada proses OTP. Salah satunya dengan metode Linear Congruential Generator (LCG) yang mampu menghindari penggunaan kunci yang rekursif dengan menentukan rentang nilai a, nilai c, dan nilai m pada metode LCG [11]. Lebih lanjut lagi dengan penggunaan pembangkit bilangan acak diharapkan akan lebih menyulitkan kriptanalis atau orang yang ingin memecahkan kode untuk kepentingan pribadi dan merugikan orang lain dalam memecakan data [4].

Penelitian yang dilakukan Kwasi Boakye-Boateng dan Arash Habibi Lashkari [12] menjelaskan tentang penggunaan OTP untuk mengamankan protokol GOOSE sangat memungkinkan karena kunci generasi dari PRNG (pseudo-random number generator) tampak benar benar acak. Akan tetapi, implementasi PRNG terlihat bersifat deterministik atau menghasilkan output yang sama. Oleh karena itu membutuhkan penyegaran / pembaharuan terutama fokus pada pembaharuan inputan PRNG. Penelitian yang dilakukan N. Khairina, M. Harahap, A. Husein et al [13] menghasilkan kunci acak dengan menggunakan algoritma Rivest Shamir Adleman (RSA) dan mengkombinasikan dengan algoritma Quadratic Congruential Generator (QCG) yang menunjukkan bahwa setiap plaintext masing - masing memiliki nilai p, q, kunci private, dan kunci pribadi yang sangat unik. Namun, hasil dari penggunaan nilai unik tersebut dapat mencegah terhadap serangan cryptanalyst sebesar $64 \%$. Selanjutnya, penelitian yang dilakukan Rachmat Aulia, A. Zakir, dan Muhammad Zulhafiz [14] melakukan kombinasi OTP dan LCG untuk mengamankan pesan teks sebelum dikirim ke target yang dituju. Hasil dari kombinasi algoritma ini didapatkan kunci acak yang berbeda setiap karakter teks pada pesan. Namun, konversi dari plaintext ke ciphertext cukup rentan untuk dilakukan cryptanalyst karena satu karakter terkonversi dengan satu karakter juga.

Untuk itu dalam penelitian ini akan dikembangkan metode penggabungan LCG atau Coupled Linear Congruential Generator untuk pembangkitan nilai acak yang sulit untuk dipecahkan. Nilai dari hasil perhitungan OTP dan CLCG, selanjutnya akan dikonversi ke dalam bentuk tabel periodik dengan menyesuaikan nomor atom yang telah didefinisikan terlebih dahulu dan mengambil variabel simbol dan konfigurasi elektronnya.

\section{METODOLOGI PENELITIAN}

Metode penelitian merupakan suatu proses atau cara yang digunakan untuk menyelesaikan masalah yang diajukan dalam sebuah penelitian dengan sekumpulan prosedur yang dilakukan oleh peneliti untuk untuk mencapai tujuan dan menentukan jawaban atas masalah yang diajukan. Adapun metode penelitian yang digunakan dapat dilihat pada gambar 1 .

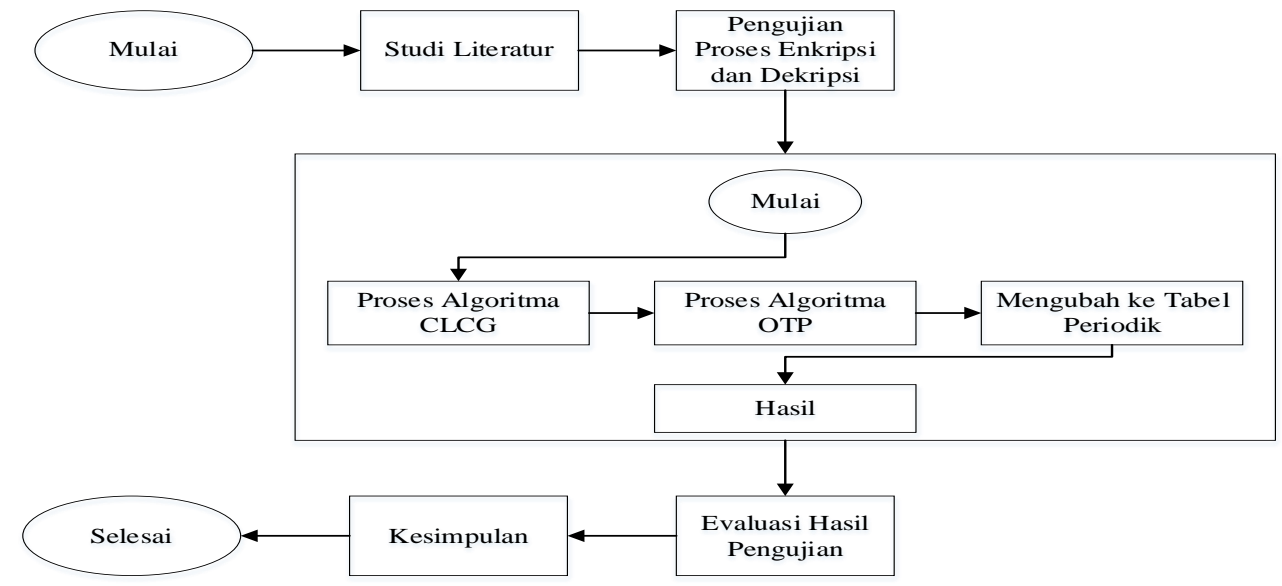

Gambar 1. Metode Penelitian

\subsection{Studi Literatur}

Menurut Sugiyono [15] "studi literatur merupakan kajian teoritis dan referensi lain yang berkaitan dengan nilai, budaya dan norma yang berkembang pada situasi sosial yang diteliti, selain itu studi kepustakaan sangat penting dalam melakukan penelitian, hal ini dikarenakan penelitian tidak akan lepas dari literatur-literatur Ilmiah."

\subsection{Pengujian Proses Enkripsi dan Dekripsi}

\subsubsection{Matrik}

Definisi matrik menurut Kaufman [16] adalah jajaran bilangan yang disusun dalam baris dan kolom diantara tanda kurung yang disusun menurut $m$ baris dan $n$ kolom sehingga membentuk jajaran (array) persegi maupun persegi panjang. Matrik yang memiliki baris dan kolom disebut matrik $m \times n$ atau matrik berorde $m \times n$. Suatu matrik ditunjukkan dengan menuliskan jajarannya di antara kurung siku, misalnya: 


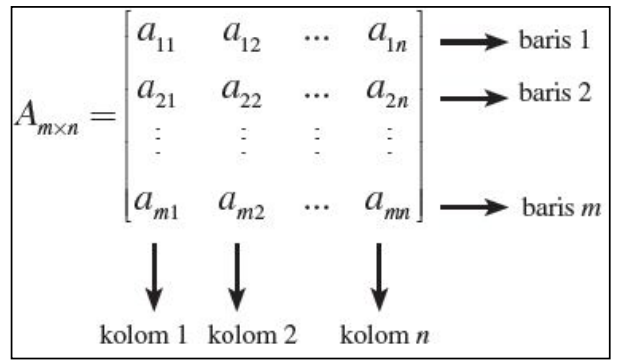

Gambar 2. Matrik

Sebuah matrik yang hanya memiliki satu baris disebut vektor baris atau matrik baris, dan sebuah matrik yang hanya memiliki satu kolom disebut vektor kolom atau matrik kolom. Sebagai contoh matrik yang akan digunakan pada penelitian ini adalah matrik 9 x 14 dengan jumlah keseluruhan 126.

Tabel 1. Matrik Ordo 9 x 14

\begin{tabular}{ccccccccccccccc}
\hline Indeks & $\mathbf{0}$ & $\mathbf{1}$ & $\mathbf{2}$ & $\mathbf{3}$ & $\mathbf{4}$ & $\mathbf{5}$ & $\mathbf{6}$ & $\mathbf{7}$ & $\mathbf{8}$ & $\mathbf{9}$ & $\mathbf{1 0}$ & $\mathbf{1 1}$ & $\mathbf{1 2}$ & $\mathbf{1 3}$ \\
\hline $\mathbf{0}$ & 1 & 2 & 3 & 4 & 5 & 6 & 7 & 8 & 9 & 10 & 11 & 12 & 13 & 14 \\
$\mathbf{1}$ & 15 & 16 & 17 & 18 & 19 & 20 & 21 & 22 & 23 & 24 & 25 & 26 & 27 & 28 \\
$\mathbf{2}$ & 29 & 30 & 31 & 32 & 33 & 34 & 35 & 36 & 37 & 38 & 39 & 40 & 41 & 42 \\
$\mathbf{3}$ & 43 & 44 & 45 & 46 & 47 & 48 & 49 & 50 & 51 & 52 & 53 & 54 & 55 & 56 \\
$\mathbf{4}$ & 57 & 58 & 59 & 60 & 61 & 62 & 63 & 64 & 65 & 66 & 67 & 68 & 69 & 70 \\
$\mathbf{5}$ & 71 & 72 & 73 & 74 & 75 & 76 & 77 & 78 & 79 & 80 & 81 & 82 & 83 & 84 \\
$\mathbf{6}$ & 85 & 86 & 87 & 88 & 89 & 90 & 91 & 92 & 93 & 94 & 95 & 96 & 97 & 98 \\
$\mathbf{7}$ & 99 & 100 & 101 & 102 & 103 & 104 & 105 & 106 & 107 & 108 & 109 & 110 & 111 & 112 \\
$\mathbf{8}$ & 113 & 114 & 115 & 116 & 117 & 118 & 119 & 120 & 121 & 122 & 123 & 124 & 125 & 126 \\
\hline
\end{tabular}

\subsubsection{Coupled Linear Congruential (CLCG)}

Metode Coupled Linear Congruential Generator adalah sebuah metode pembangkit bilangan acak semu yang memanfaatkan penggabungan dua persamaan linear berbasis metode Linear Congruential Generator sebagai generasi baru pembangkit bilangan acak [17]. Metode Coupled Linear Congruential Generator didefinisikan dengan persamaan :

$$
\begin{aligned}
& x_{i+1}=a_{1} x_{i}+b_{1}(\bmod m) \\
& y_{i+1}=a_{2} y_{i}+b_{2}(\bmod m)
\end{aligned}
$$

Keterangan :

$$
\begin{aligned}
& x_{i+1}=\text { bilangan acak } x \text { ke- } n \text { dari deret nya } \\
& y_{i+1}=\text { bilangan acak } y \text { ke- } n \text { dari deretnya } \\
& x_{n} \quad=\text { bilangan acak } x \text { dari sebelumnya } \\
& y_{n} \quad=\text { bilangan acak } y \text { dari sebelumnya } \\
& a \quad=\text { faktor pengali } \\
& \text { b } \quad \text { increment } \\
& \mathrm{m} \quad=\text { modulus } \\
& i \quad=0,1,2,3, \ldots \text { dan seterunya. }
\end{aligned}
$$

Pengembangan metode Coupled Linear Congruential Generator yang dilakukan oleh Katti digunakan untuk menghasilkan enkripsi deret bit $B_{i}$ dengan kondisi :

$$
B_{i+1}=\left\{\begin{array}{ll}
1, & \text { jika } x_{i+1}>y_{i+1} \\
0, & \text { sebaliknya }
\end{array}\right\}
$$

Metode Coupled Linear Congruential Generator dimodifikasi dengan matrik. Berdasarkan hasil persamaan $x_{i+1}$ dan $y_{i+1}$ maka akan didapatkan deret bilangan acak yang akan dirubah ke dalam bilangan orde matrik. Orde $x$ didapatkan dari modulus $x_{i+1}$ terhadap jumlah baris dengan persamaan :

$$
M_{(x, 0)}=x_{i+1} \bmod i
$$

Orde $y$ didapatkan dari modulus $y_{i+1}$ terhadap jumlah kolom dengan persamaan :

$$
M_{(0, \mathrm{y})}=y_{i+1} \bmod j
$$

Hasil akhir didapatkan dengan menggunakan matrik baru dari persamaan :

$$
M_{n}=M\left[x_{i+1} \bmod i\right]\left[y_{i+1} \bmod j\right]
$$

Keterangan

$\begin{array}{ll}M_{n} & =\text { hasil bilangan acak ke- } n \text { dari deretnya } \\ x_{i+1} & =\text { bilangan acak } x \text { ke- } n \text { dari deretnya }\end{array}$ 


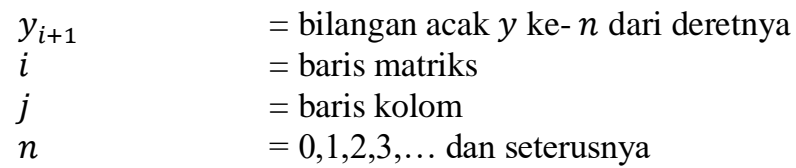

Contoh hasil perhitungan pembangkitan bilangan acak dengan CLCG sebanyak 10 kali sebagai berikut :

Diketahui

$\begin{aligned} \text { Matrik baris } & =9 \\ \text { Matrik kolom } & =14 \\ \text { X0 (baris) } & =4 \\ Y 0(\text { kolom }) & =5 \\ a & =64 \\ b & =17 \\ m & =126\end{aligned}$

Tabel 2. Perhitungan CLCG sebanyak 10 kali

\begin{tabular}{ccccccc}
\hline $\mathbf{X}$ & Nilai & Y & Nilai & Baris & Kolom & Hasil \\
\hline $\mathbf{X 1}$ & 21 & Y1 & 85 & 3 & 1 & 44 \\
$\mathbf{X 2}$ & 101 & Y2 & 39 & 2 & 11 & 40 \\
$\mathbf{X 3}$ & 55 & Y3 & 119 & 1 & 7 & 22 \\
$\mathbf{X 4}$ & 9 & Y4 & 73 & 0 & 3 & 4 \\
$\mathbf{X 5}$ & 89 & Y5 & 27 & 8 & 13 & 126 \\
$\mathbf{X 6}$ & 43 & Y6 & 107 & 7 & 9 & 108 \\
$\mathbf{X 7}$ & 123 & Y7 & 61 & 6 & 5 & 90 \\
$\mathbf{X 8}$ & 77 & Y8 & 15 & 5 & 1 & 72 \\
$\mathbf{X 9}$ & 31 & Y9 & 95 & 4 & 11 & 68 \\
$\mathbf{X 1 0}$ & 111 & Y10 & 49 & 3 & 7 & 50 \\
\hline
\end{tabular}

\subsubsection{One Time Pad (OTP)}

Algortima OTP pertama kali ditemukan oleh Gilbert Vernam di tahun 1917 menggunakan karakter-karakter kunci yang berisi huruf-huruf yang tersusun secara acak. OTP merupakan salah satu algoritma yang populer dan sering digunakan dalam teknik kriptografi di jaman modern saat ini. Algoritma OTP termasuk kelompok algoritma simetris dalam teknik kriptografi dimana kunci enkripsi dan dekripsi dalam bentuk dan panjang yang sama dengan plaintext atau teks aslinya, serta menggunakan operasi XOR dalam proses enkripsi dan dekripsinya [18]. Keunggulan dari algoritma OTP adalah sangat sulit dan rumit untuk dipecahkan tapi memiliki kekurangan dimana kunci yang digunakan kadang terlalu panjang karena harus menyesuaikan jumlah karakter plaintext yang akan dienkripsi [19]. Dari semua algoritma kriptografi yang telah dirancang, algoritma OTP adalah metode yang telah terbukti benar-benar aman secara matematis. Algoritma OTP bisa dikatakan algoritma yang 'sempurna' jika memenuhi kondisi seperti berikut [20] kunci harus sepanjang dengan plainteks, kunci harus tersusun secara acak seluruhnya atau sepenuhnya berbeda, kunci hanya sekali digunakan pada setiap melakukan proses enkripsi, dan hanya terdapat dua salinan dari kunci: satu untuk pengirim dan satu untuk penerima [21]. Rumus enkripsi dan dekripsi OTP dalam dijabarkan melalui Persamaan 7 dan Persamaan 8 [22].

$$
\begin{aligned}
& C i=(P i+K i) \bmod X \\
& P i=(C i-K i) \bmod X
\end{aligned}
$$

dimana:

$$
\begin{aligned}
& \text { Ci }=\text { Ciphertext } \\
& P i=\text { Plaintext } \\
& K i=\text { Kunci } \\
& \text { mod } X=\text { nilai maksimal kunci }
\end{aligned}
$$

\subsubsection{Tabel Periodik}

Tabel periodik unsur berisi unsur-unsur kimia yang tersusun sesuai ketetapan nomor atom dan konfigurasi elektron. Unsur tersebut disusun berdasarkan nomer atomnya dan dibagi menjadi 2 susunan, susunan baris terdiri dari 7 periode, susunan kolom terbagi menjadi 8 golongan. Setiap unsur didaftarkan berdasarkan nomor atom dan lambang unsur [23]. Dalam tabel periodik hanya 2 kategori yang akan digunakan untuk meng-enkripsi pesan yaitu simbol dan konfigurasi elektron. Dalam penelitian ini Tabel Periodik ditambahkan 8 karakter untuk melengkapi Tabel ASCII sebanyak 126 yang akan digunakan. Adapun tabel yang akan digunakan akan ditunjukan pada Tabel 3. sebagai berikut: 
JURNAL MEDIA INFORMATIKA BUDIDARMA

Volume 4, Nomor 3, Juli 2020, Page 841-849

ISSN 2614-5278 (media cetak), ISSN 2548-8368 (media online)

Available Online at https://ejurnal.stmik-budidarma.ac.id/index.php/mib

DOI 10.30865/mib.v4i3.2244

Tabel 3. Tabel Periodik

\begin{tabular}{|c|c|c|c|c|c|}
\hline $\begin{array}{c}\text { Atomic } \\
\text { Number }\end{array}$ & $\underset{1}{\text { Symbo }}$ & $\begin{array}{c}\dagger \text { Electron } \\
\text { Configuration }\end{array}$ & $\begin{array}{c}\text { Atomic } \\
\text { Number }\end{array}$ & $\begin{array}{c}\text { Symb } \\
\text { ol }\end{array}$ & $\begin{array}{c}\dagger \text { Electron } \\
\text { Configuration }\end{array}$ \\
\hline $\mathbf{1}$ & $\mathrm{H}$ & $1 \mathrm{~s} 1$ & 64 & $\mathrm{Gd}$ & {$[\mathrm{Xe}] 4 \mathrm{f} 75 \mathrm{~d} 16 \mathrm{~s} 2$} \\
\hline 2 & $\mathrm{He}$ & $1 \mathrm{~s} 2$ & 65 & $\mathrm{~Tb}$ & {$[\mathrm{Xe}] 4 \mathrm{f} 96 \mathrm{~s} 2$} \\
\hline 3 & $\mathrm{Li}$ & {$[\mathrm{He}] 2 \mathrm{~s} 1$} & 66 & Dy & {$[\mathrm{Xe}] 4 \mathrm{f} 10 \mathrm{6s} 2$} \\
\hline 4 & $\mathrm{Be}$ & {$[\mathrm{He}] 2 \mathrm{~s} 2$} & 67 & Ho & {$[\mathrm{Xe}] 4 \mathrm{f} 116 \mathrm{~s} 2$} \\
\hline 5 & B & {$[\mathrm{He}] 2 \mathrm{~s} 2 \mathrm{2p} 1$} & 68 & $\mathrm{Er}$ & [Xe] 4f12 6s 2 \\
\hline 6 & $\mathrm{C}$ & {$[\mathrm{He}] 2 \mathrm{~s} 2 \mathrm{2p} 2$} & 69 & $\mathrm{Tm}$ & {$[\mathrm{Xe}] 4 \mathrm{f} 136 \mathrm{~s} 2$} \\
\hline 7 & $\mathrm{~N}$ & {$[\mathrm{He}] 2 \mathrm{~s} 22 \mathrm{p} 3$} & 70 & $\mathrm{Yb}$ & {$[\mathrm{Xe}] 4 \mathrm{f} 146 \mathrm{~s} 2$} \\
\hline 8 & $\mathrm{O}$ & {$[\mathrm{He}] 2 \mathrm{~s} 2 \mathrm{2p} 4$} & 71 & $\mathrm{Lu}$ & [Xe] 4f14 5d16s2 \\
\hline 9 & $\mathrm{~F}$ & {$[\mathrm{He}] 2 \mathrm{~s} 2 \mathrm{2p} 5$} & 72 & Hf & {$[\mathrm{Xe}] 4 \mathrm{f} 145 \mathrm{~d} 26 \mathrm{~s} 2$} \\
\hline 10 & $\mathrm{Ne}$ & {$[\mathrm{He}] 2 \mathrm{~s} 22 \mathrm{p} 6$} & 73 & $\mathrm{Ta}$ & {$[\mathrm{Xe}] 4 \mathrm{f} 145 \mathrm{~d} 3 \mathrm{6s} 2$} \\
\hline 11 & $\mathrm{Na}$ & [Ne] 3s1 & 74 & $\mathrm{~W}$ & {$[\mathrm{Xe}] 4 \mathrm{f} 145 \mathrm{~d} 46 \mathrm{~s} 2$} \\
\hline 12 & $\mathrm{Mg}$ & {$[\mathrm{Ne}] 3 \mathrm{~s} 2$} & 75 & $\mathrm{Re}$ & {$[\mathrm{Xe}] 4 \mathrm{f} 145 \mathrm{~d} 5 \mathrm{6s} 2$} \\
\hline 13 & $\mathrm{Al}$ & {$[\mathrm{Ne}] 3 \mathrm{~s} 23 \mathrm{p} 1$} & 76 & Os & [Xe] 4f14 5d6 6s2 \\
\hline 14 & $\mathrm{Si}$ & {$[\mathrm{Ne}] 3 \mathrm{~s} 23 \mathrm{p} 2$} & 77 & Ir & {$[\mathrm{Xe}] 4 \mathrm{f} 145 \mathrm{~d} 76 \mathrm{~s} 2$} \\
\hline 15 & $\mathrm{P}$ & {$[\mathrm{Ne}] 3 \mathrm{~s} 23 \mathrm{p} 3$} & 78 & $\mathrm{Pt}$ & [Xe] 4f14 5d9 6s1 \\
\hline 16 & $\mathrm{~S}$ & {$[\mathrm{Ne}] 3 \mathrm{~s} 23 \mathrm{p} 4$} & 79 & $\mathrm{Au}$ & {$[\mathrm{Xe}] 4 \mathrm{f} 145 \mathrm{~d} 10 \mathrm{6s} 1$} \\
\hline 17 & $\mathrm{Cl}$ & {$[\mathrm{Ne}] 3 \mathrm{~s} 23 \mathrm{p} 5$} & 80 & $\mathrm{Hg}$ & {$[\mathrm{Xe}] 4 \mathrm{f} 14 \mathrm{dd} 10 \mathrm{6s} 2$} \\
\hline 18 & $\mathrm{Ar}$ & {$[\mathrm{Ne}] 3 \mathrm{~s} 23 \mathrm{p} 6$} & 81 & $\mathrm{Tl}$ & {$[\mathrm{Hg}] 6 \mathrm{p} 1$} \\
\hline 19 & $\mathrm{~K}$ & [Ar] 4s1 & 82 & $\mathrm{~Pb}$ & {$[\mathrm{Hg}] 6 \mathrm{p} 2$} \\
\hline 20 & $\mathrm{Ca}$ & [Ar] 4s 2 & 83 & $\mathrm{Bi}$ & {$[\mathrm{Hg}] 6 \mathrm{p} 3$} \\
\hline 21 & $\mathrm{Sc}$ & [Ar] $3 \mathrm{~d} 14 \mathrm{~s} 2$ & 84 & $\mathrm{Po}$ & {$[\mathrm{Hg}] 6 \mathrm{p} 4$} \\
\hline 22 & $\mathrm{Ti}$ & {$[\mathrm{Ar}] 3 \mathrm{~d} 24 \mathrm{~s} 2$} & 85 & At & {$[\mathrm{Hg}] 6 \mathrm{p} 5$} \\
\hline 23 & V & {$[\mathrm{Ar}] 3 \mathrm{~d} 34 \mathrm{~s} 2$} & 86 & $\mathrm{Rn}$ & {$[\mathrm{Hg}] 6 \mathrm{p} 6$} \\
\hline 24 & $\mathrm{Cr}$ & {$[\mathrm{Ar}] 3 \mathrm{~d} 5 \mathrm{ss} 1$} & 87 & $\mathrm{Fr}$ & [Rn] 7s1 \\
\hline 25 & Mn & [Ar] $3 \mathrm{~d} 5 \mathrm{4s} 2$ & 88 & $\mathrm{Ra}$ & {$[\mathrm{Rn}] 7 \mathrm{~s} 2$} \\
\hline 26 & $\mathrm{Fe}$ & [Ar] $3 \mathrm{~d} 64 \mathrm{~s} 2$ & 89 & Ac & [Rn] 6d1 7s2 \\
\hline 27 & $\mathrm{Co}$ & {$[\mathrm{Ar}] 3 \mathrm{~d} 74 \mathrm{~s} 2$} & 90 & $\mathrm{Th}$ & {$[\mathrm{Rn}] 6 \mathrm{~d} 27 \mathrm{~s} 2$} \\
\hline 28 & $\mathrm{Ni}$ & {$[\mathrm{Ar}] 3 \mathrm{~d} 84 \mathrm{~s} 2$} & 91 & $\mathrm{~Pa}$ & {$[\mathrm{Rn}] 5 \mathrm{f} 26 \mathrm{~d} 17 \mathrm{~s} 2$} \\
\hline 29 & $\mathrm{Cu}$ & [Ar] 3d10 4s 1 & 92 & $\mathrm{U}$ & {$[\mathrm{Rn}] 5 \mathrm{f} 36 \mathrm{~d} 17 \mathrm{~s} 2$} \\
\hline 30 & $\mathrm{Zn}$ & [Ar] 3d10 4s 2 & 93 & $\mathrm{~Np}$ & {$[\mathrm{Rn}] 5 \mathrm{f} 46 \mathrm{~d} 1 \mathrm{7s} 2$} \\
\hline 31 & $\mathrm{Ga}$ & [Ar] 3d10 4s $24 \mathrm{p} 1$ & 94 & $\mathrm{Pu}$ & {$[\mathrm{Rn}] 5 \mathrm{f} 6 \mathrm{7s} 2$} \\
\hline 32 & $\mathrm{Ge}$ & [Ar] $3 \mathrm{~d} 104 \mathrm{~s} 24 \mathrm{p} 2$ & 95 & Am & [Rn] 5f7 7s2 \\
\hline 33 & As & [Ar] 3d10 4s $24 \mathrm{p} 3$ & 96 & $\mathrm{Cm}$ & {$[\mathrm{Rn}] 5 \mathrm{f} 76 \mathrm{~d} 7 \mathrm{~s} 2$} \\
\hline 34 & $\mathrm{Se}$ & [Ar] 3d10 4s $24 \mathrm{p} 4$ & 97 & $\mathrm{Bk}$ & {$[\mathrm{Rn}] 5 \mathrm{f9} 7 \mathrm{~s} 2$} \\
\hline 35 & $\mathrm{Br}$ & {$[\mathrm{Ar}] 3 \mathrm{~d} 104 \mathrm{~s} 2 \mathrm{pp} 5$} & 98 & $\mathrm{Cf}$ & {$[\mathrm{Rn}] 5 \mathrm{f} 107 \mathrm{~s} 2$} \\
\hline 36 & $\mathrm{Kr}$ & [Ar] 3d10 4s $24 \mathrm{p} 6$ & 99 & Es & {$[\mathrm{Rn}] 5 \mathrm{f} 11 \mathrm{7s} 2$} \\
\hline 37 & $\mathrm{Rb}$ & {$[\mathrm{Kr}] 5 \mathrm{~s} 1$} & 100 & $\mathrm{Fm}$ & {$[\mathrm{Rn}] 5 \mathrm{f} 12 \mathrm{ss} 2$} \\
\hline 38 & $\mathrm{Sr}$ & {$[\mathrm{Kr}] 5 \mathrm{~s} 2$} & 101 & Md & [Rn] $5 \mathrm{f} 13$ 7s 2 \\
\hline 39 & $\mathrm{Y}$ & {$[\mathrm{Kr}] 4 \mathrm{~d} 15 \mathrm{~s} 2$} & 102 & No & [Rn] 5f14 7s2 \\
\hline 40 & $\mathrm{Zr}$ & {$[\mathrm{Kr}] 4 \mathrm{~d} 25 \mathrm{~s} 2$} & 103 & $\mathrm{Lr}$ & {$[\mathrm{Rn}] 5 \mathrm{f} 14 \mathrm{7s} 2 \mathrm{7p} ?$} \\
\hline 41 & $\mathrm{Nb}$ & {$[\mathrm{Kr}] 4 \mathrm{~d} 45 \mathrm{~s} 1$} & 104 & $\mathrm{Rf}$ & {$[\mathrm{Rn}] 5 \mathrm{f} 146 \mathrm{~d} 27 \mathrm{~s} 2 ?$} \\
\hline 42 & Mo & {$[\mathrm{Kr}] 4 \mathrm{~d} 5 \mathrm{ss} 1$} & 105 & $\mathrm{Db}$ & \\
\hline 43 & $\mathrm{Tc}$ & {$[\mathrm{Kr}] 4 \mathrm{~d} 5 \mathrm{ss} 2$} & 106 & $\mathrm{Sg}$ & \\
\hline 44 & $\mathrm{Ru}$ & {$[\mathrm{Kr}] 4 \mathrm{~d} 75 \mathrm{~s} 1$} & 107 & $\mathrm{Bh}$ & \\
\hline 45 & $\mathrm{Rh}$ & {$[\mathrm{Kr}] 4 \mathrm{~d} 85 \mathrm{~s} 1$} & 108 & Hs & \\
\hline 46 & $\mathrm{Pd}$ & {$[\mathrm{Kr}] 4 \mathrm{~d} 10$} & 109 & Mt & \\
\hline 47 & $\mathrm{Ag}$ & {$[\mathrm{Kr}] 4 \mathrm{~d} 105 \mathrm{~s} 1$} & 110 & Ds & \\
\hline 48 & $\mathrm{Cd}$ & {$[\mathrm{Kr}] 4 \mathrm{~d} 105 \mathrm{~s} 2$} & 111 & $\mathrm{Rg}$ & \\
\hline 49 & In & {$[\mathrm{Kr}] 4 \mathrm{~d} 105 \mathrm{~s} 25 \mathrm{p} 1$} & 112 & $\mathrm{Cn}$ & \\
\hline 50 & $\mathrm{Sn}$ & {$[\mathrm{Kr}] 4 \mathrm{~d} 105 \mathrm{~s} 25 \mathrm{p} 2$} & 113 & Uut & \\
\hline 51 & $\mathrm{Sb}$ & {$[\mathrm{Kr}] 4 \mathrm{~d} 105 \mathrm{~s} 25 \mathrm{p} 3$} & 114 & Uuq & \\
\hline 52 & $\mathrm{Te}$ & {$[\mathrm{Kr}] 4 \mathrm{~d} 105 \mathrm{~s} 25 \mathrm{p} 4$} & 115 & Uup & \\
\hline 53 & I & {$[\mathrm{Kr}] 4 \mathrm{~d} 105 \mathrm{~s} 25 \mathrm{p} 5$} & 116 & Uuh & \\
\hline 54 & $\mathrm{Xe}$ & {$[\mathrm{Kr}] 4 \mathrm{~d} 105 \mathrm{~s} 25 \mathrm{p} 6$} & 117 & Uus & \\
\hline 55 & Cs & {$[\mathrm{Xe}] 6 \mathrm{~s} 1$} & 118 & Uuo & \\
\hline 56 & $\mathrm{Ba}$ & {$[\mathrm{Xe}] 6 \mathrm{~s} 2$} & 119 & $!$ & \\
\hline 57 & $\mathrm{La}$ & {$[\mathrm{Xe}] 5 \mathrm{~d} 16 \mathrm{~s} 2$} & 120 & @ & \\
\hline 58 & $\mathrm{Ce}$ & {$[\mathrm{Xe}] 4 \mathrm{f} 15 \mathrm{~d} 16 \mathrm{~s} 2$} & 121 & \# & \\
\hline
\end{tabular}


JURNAL MEDIA INFORMATIKA BUDIDARMA

Volume 4, Nomor 3, Juli 2020, Page 841-849

ISSN 2614-5278 (media cetak), ISSN 2548-8368 (media online)

Available Online at https://ejurnal.stmik-budidarma.ac.id/index.php/mib

DOI 10.30865/mib.v4i3.2244

\begin{tabular}{cccccc}
\hline $\begin{array}{c}\text { Atomic } \\
\text { Number }\end{array}$ & $\begin{array}{c}\text { Symbo } \\
\text { l }\end{array}$ & $\begin{array}{c}\dagger \text { Electron } \\
\text { Configuration }\end{array}$ & $\begin{array}{c}\text { Atomic } \\
\text { Number }\end{array}$ & $\begin{array}{c}\text { Symb } \\
\text { ol }\end{array}$ & $\begin{array}{c}\dagger \text { Electron } \\
\text { Configuration }\end{array}$ \\
\hline $\mathbf{5 9}$ & $\mathrm{Pr}$ & {$[\mathrm{Xe}] 4 \mathrm{f} 36 \mathrm{~s} 2$} & 122 & $\$$ & \\
$\mathbf{6 0}$ & $\mathrm{Nd}$ & {$[\mathrm{Xe}] 4 \mathrm{f} 46 \mathrm{~s} 2$} & 123 & $\%$ & \\
$\mathbf{6 1}$ & $\mathrm{Pm}$ & {$[\mathrm{Xe}] 4 \mathrm{f} 56 \mathrm{~s} 2$} & 124 & $?$ & \\
$\mathbf{6 2}$ & $\mathrm{Sm}$ & {$[\mathrm{Xe}] 4 \mathrm{f} 66 \mathrm{~s} 2$} & 125 & $\&$ & \\
$\mathbf{6 3}$ & $\mathrm{Eu}$ & {$[\mathrm{Xe}] 4 \mathrm{f} 76 \mathrm{~s} 2$} & 126 & ) & \\
\hline
\end{tabular}

\section{HASIL DAN PEMBAHASAN}

Pada penelitan ini alur untuk proses enkripsi dan dekripsi akan ditunjukkan pada Gambar 3. dan Gambar 4.

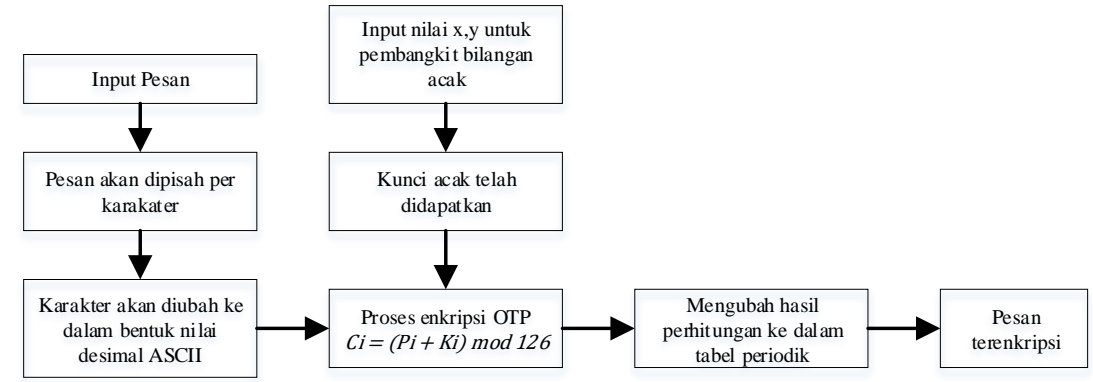

Gambar 3. Alur proses enkripsi pesan

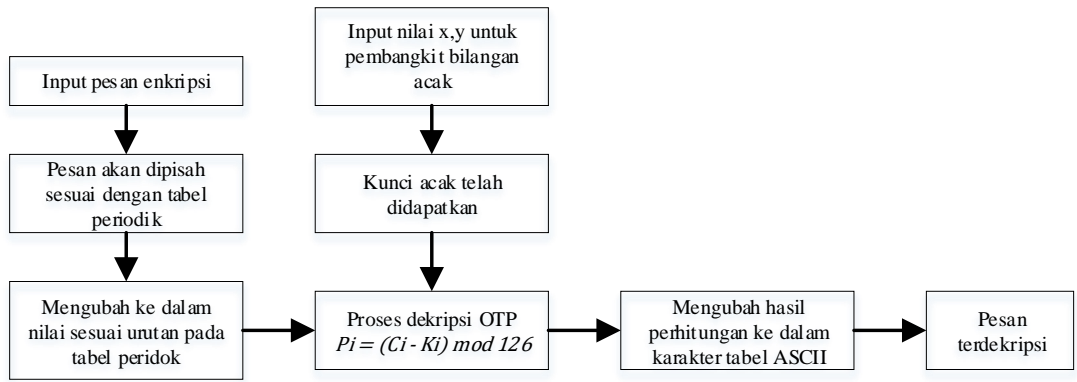

Gambar 4. Alur proses dekripsi pesan

\subsection{Proses Enkripsi}

Berikut ini proses enkripsi dari sebuah pesan (plaintext) yaitu "Saya Pergi", dimana akan terlebih dahulu dibangkitkan kunci acak sepanjang plaintext-nya menggunakan CLCG. Proses dalam melakukan penyandian dengan menggunakan metode OTP pada Persamaan (7) dan kunci acak pada Tabel 2 akan ditunjukkan pada Tabel 4. berikut ini :

Contoh perhitungan OTP pada proses enkripsi pesan :

Diketahui karakter "S" memiliki nilai ASCII 83, dengan kunci CLCG 44, maka hasil enkripsinya adalah :

$=(83+44) \operatorname{Mod} 126$,

$=127 \operatorname{Mod} 126$,

$=1$, karena sisa bagi 127: 126 adalah 1

Sehingga nilai 1 pada Tabel Periodik adalah He1s2

Tabel 4. Proses Enkripsi Pesan

\begin{tabular}{ccccc}
\hline Plaintext & ASCII & Kunci CLCG & Tabel Periodik & Enkripsi \\
\hline $\mathbf{S}$ & 83 & 44 & 1 & He1s2 \\
$\mathbf{a}$ & 97 & 40 & 11 & Mg3s 2 \\
$\mathbf{y}$ & 121 & 22 & 17 & Ar3s23p6 \\
$\mathbf{a}$ & 97 & 4 & 101 & No5f147s2 \\
spasi & 32 & 126 & 32 & As3d104s24p3 \\
$\mathbf{p}$ & 112 & 108 & 94 & Am5f77s2 \\
$\mathbf{e}$ & 101 & 90 & 65 & Dy4f106s2 \\
$\mathbf{r}$ & 114 & 72 & 60 & Pm4f56s2 \\
$\mathbf{g}$ & 103 & 68 & 45 & Pd4d10 \\
$\mathbf{i}$ & 105 & 50 & 29 & Zn3d104s2 \\
\hline
\end{tabular}


ISSN 2614-5278 (media cetak), ISSN 2548-8368 (media online)

Available Online at https://ejurnal.stmik-budidarma.ac.id/index.php/mib

DOI 10.30865/mib.v4i3.2244

Maka hasil enkripsinya adalah $=$

He1s2Mg3s2Ar3s23p6No5f147s2As3d104s24p3Am5f77s2Dy4f106s2Pm4f56s2Pd4d10Zn3d104s2

Adapun pengujian proses enkripsi tidak hanya dilakukan pada contoh kasus pada Tabel 4. Namun, pengujian dilakukan pada beberapa plaintext yang ditunjukkan pada Tabel 5. sebagai berikut :

Tabel 5. Proses Enkripsi

\begin{tabular}{|c|c|c|c|}
\hline No. & Plaintext & $\begin{array}{l}\text { Kunci } \\
\text { x dan y }\end{array}$ & Ciphertext \\
\hline $\mathbf{1}$ & $\begin{array}{l}\text { Hati-Hati Akan } \\
\text { Ada } \\
\text { Perkumpulan } \\
\text { Jam } 12.00 \\
\text { Tengah Malam }\end{array}$ & $\begin{array}{l}X=10 \\
Y=14\end{array}$ & $\begin{array}{l}\text { Ir4f145d76s2Cf5f107s2Es5f117s2Yb4f146s2UuoP3s23p3Ti3d24s2V3 } \\
\text { d34s2O2s22p4Tc4d55s2Ce4f15d16s2Pb6p2Er4f126s2Eu4f76s2Np5f } \\
\text { 46d17s2\$Al3s23p1UuoBr3d104s24p5Au4f145d106s1Pb6p2Ir4f145d } \\
\text { 76s2Dy4f106s2Ce4f15d16s2Ge3d104s24p2Cl3s23p5Ar3s23p6UusRa } \\
\text { 7s2Bk5f97s2H1s1Ga3d104s24p1Zn3d104s2Cu3d104s1O2s22p4Sb4d } \\
\text { 105s25p3Ac6d17s2Pu5f67s2Ra7s2!C2s22p2UupNp5f46d17s2Pa5f26 } \\
\text { d17s2Ta4f145d36s2Y4d15s2Ta4f145d36s2Rn6p6Ir4f145d76s2Te4d1 } \\
\text { 05s25p4Mo4d55s1Ga3d104s24p1Ho4f116s2Pu5f67s2DsLr5f147s27p } \\
\text { ?W4f145d46s2Pb6p2 }\end{array}$ \\
\hline 2 & Terima Kasih & $\begin{array}{l}X=25 \\
Y=20\end{array}$ & $\begin{array}{l}\text { I4d105s25p5Te4d105s25p4Ag4d105s1Se3d104s24p4Ca4s2UuhAg4d } \\
\text { 105s1Hf4f145d26s2Os4f145d66s2Os4f145d66s2Sm4f66s2Tc4d55s2 }\end{array}$ \\
\hline 3 & Awas! & $\begin{array}{l}X=2 \\
Y=27\end{array}$ & Th6d27s2)Rn6p6Fm5f127s2) \\
\hline
\end{tabular}

\subsection{Proses Dekripsi}

Dalam melakukan proses pengembalian ciphertext menjadi plaintext dapat dilihat pada Persamaan 2.8 , kunci yang akan digunakan sama dengan proses enkripsi dengan menggunakan CLCG yang terdapat pada Tabel 2. Cara memisahkan ciphertext untuk 1 (satu) karakter yang selanjutnya akan diubah menjadi nilai, dengan cara memotong akhir nilai sebelum huruf kapital dalam ciphertext. Berikut ini pada Tabel 6. merupakan proses dekripsi nya.

Diketahui Ciphertext He1s2 memiliki nilai 1 pada Tabel Periodik dengan kunci yang sama seperti proses enkripsi 44, maka perhitungan proses dekripsinya sebagai berikut :

$$
\begin{aligned}
& =(1-44) \text { Mod } 126, \\
& =-43 \text { Mod } 126, \\
& =83, \text { karena sisa bagi }-43: 126 \text { adalah } 83
\end{aligned}
$$

Sehingga nilai ASCII 83 adalah karakter "S"

Tabel 6. Proses Dekripsi Pesan

\begin{tabular}{ccccc}
\hline Ciphertext & Tabel Periodik & Kunci CLCG & ASCII & Plaintext \\
\hline He1s2 & 1 & 44 & 83 & $\mathrm{~S}$ \\
Mg3s2 & 11 & 40 & 97 & $\mathrm{a}$ \\
Ar3s23p6 & 17 & 22 & 121 & $\mathrm{y}$ \\
No5f147s2 & 101 & 4 & 97 & $\mathrm{a}$ \\
As3d104s24p3 & 32 & 126 & 32 & spasi \\
Am5f77s2 & 94 & 108 & 112 & $\mathrm{p}$ \\
Dy4f106s2 & 65 & 90 & 101 & $\mathrm{e}$ \\
Pm4f56s2 & 60 & 72 & 114 & $\mathrm{r}$ \\
Pd4d10 & 45 & 68 & 103 & $\mathrm{~g}$ \\
Zn3d104s2 & 29 & 50 & 105 & $\mathrm{i}$ \\
\hline
\end{tabular}

Maka hasil enkripsinya adalah = Saya pergi.

Adapun proses dekripsi yang dilakukan dari Tabel 5. akan ditunjukkan pada Tabel 7.

Tabel 7. Proses Dekripsi

\begin{tabular}{cccl}
\hline No. & Ciphertext & $\begin{array}{c}\text { Kunci x } \\
\text { dan y }\end{array}$ & Plaintext \\
\hline 1 & Ir4f145d76s2Cf5f107s2Es5f117s2Yb4f146s2UuoP3s23p3Ti3d24s & X=10 & Hati-Hati \\
& 2V3d34s2O2s22p4Tc4d55s2Ce4f15d16s2Pb6p2Er4f126s2Eu4f76 & Y= 14 & Akan Ada \\
& s2Np5f46d17s2\$AI3s23p1UuoBr3d104s24p5Au4f145d106s1Pb6p & & Perkumpulan \\
& 2Ir4f145d76s2Dy4f106s2Ce4f15d16s2Ge3d104s24p2C13s23p5Ar & & Jam 12.00 \\
& 3s23p6UusRa7s2Bk5f97s2H1s1Ga3d104s24p1Zn3d104s2Cu3d10 & &
\end{tabular}




\begin{tabular}{llll}
\hline & 4s1O2s22p4Sb4d105s25p3Ac6d17s2Pu5f67s2Ra7s2!C2s22p2Uup & & Tengah \\
& Np5f46d17s2Pa5f26d17s2Ta4f145d36s2Y4d15s2Ta4f145d36s2R & & Malam \\
& n6p6Ir4f145d76s2Te4d105s25p4Mo4d55s1Ga3d104s24p1Ho4f11 & & \\
& 6s2Pu5f67s2DsLr5f147s27p?W4f145d46s2Pb6p2 & \\
\multirow{2}{*}{2} & I4d105s25p5Te4d105s25p4Ag4d105s1Se3d104s24p4Ca4s2UuhA & X=25 & Terima Kasih \\
& g4d105s1Hf4f145d26s2Os4f145d66s2Os4f145d66s2Sm4f66s2Tc4 & Y=20 & \\
& d55s2 & & \\
3 & Th6d27s2)Rn6p6Fm5f127s2) & X=2 & Awas! \\
& & Y=27 & \\
\hline
\end{tabular}

\section{KESIMPULAN}

Bedasarkan dari perhitungan proses enkripsi dan dekripsi, penggunaan algoritma OTP tidak perlu memasukkan banyak kunci untuk proses tersebut. Adapun jumlah kunci yang dimasukkan hanya nilai $\mathrm{x}$ dan y sebagai nilai untuk membangkitkan bilangan acak menggunakan algoritma CLCG. Implementasi algoritma CLCG pada proses pembangkitan kunci acak terbukti tidak terjadi perulangan nilai yang sama pada karakter yang sama yang berdekatan, hal ini dikarenakan penentuan nilai a, b, dan $m$ dan juga dalam penggunaan matrik. Modifikasi dengan menggunakan tabel periodik sangat membantu untuk dalam proses enkripsi, sehingga hasil enkripsi yang didapatkan cukup sulit untuk dipecahkan karena dalam proses enkripsi satu karakter plaintext digantikan dengan beberapa karakter pada ciphertext.

\section{REFERENCES}

[1] A. Liliwer, Komunikasi Serba Ada Serba Makna, Kencana, 2010.

[2] S. M. Suryanto, Pengantar Ilmu Komunikasi, Bandung: CV. Pustaka Setia, 2015.

[3] R. Aulia, "Pemanfaatan Website Sebagai Sarana Managing Data Dalam Suatu Organisasi (Studi Kasus: Pertemuan Ilmiah Nasional (Pin) Perhimpunan Dokter Spesialis Saraf Indonesia (Perdossi) 2013 Medan)," InfoTekJar: Jurnal Nasional Informatika dan Teknolologi Jaringan, vol. I, no. 1, pp. 1-6, 2016.

[4] P. Utomo, Sapriadi dan M. Zarlis, "Algoritma Split-Merge One Time Pad Dalam Peningkatan Enkripsi Data," dalam Seminar Nasional Teknologi Informatika (SEMANTIKA), 2017.

[5] E. H. Houssein, A. A. Mona dan A. E. Hassanien, "An image steganography algorithm using haar discrete wavelet transform with advanced encryption system," dalam Federated Conference on Computer Science and Information Systems (FedCSIS)., 2016.

[6] E. H. Rachmawanto dan C. A. Sari, "A performance analysis StegoCrypt algorithm based on LSB-AES 128 bit in various image size," dalam International Seminar on Application for Technology of Information and Communication (iSemantic), 2017.

[7] H. A. Elsayed, Y. K. Jadaan dan S. K. Guirguis, "Image security using quantum Rivest-Shamir-Adleman cryptosystem algorithm and digital watermarking.," dalam Progress in Electromagnetic Research Symposium (PIERS)., 2016.

[8] D. Ariyus, Kriptografi Keamanan Data dan Komunikasi, Yogyakarta: Graha Ilmu, 2006.

[9] I. Wibowo, Susanto dan J. Karel, "Penerapan Algoritma Kriptografi Asimetris RSA untuk Keamanan Data di Oracle," Jurnal Informatika, vol. 1, no. 5, 2011.

[10] Saha, B. Jyoti, K. K. Kabi dan C. Pradhan, "Non blind watermarking technique using enhanced one time pad in DWT domain," dalam Fifth International Conference on Computing, Communications and Networking Technologies (ICCCNT), 2014.

[11] J. Clawdia, N. Khairina dan M. K. Harahap, "Implementasi Algoritma Kriptografi One Time Pad (OTP) Dengan Dynamic Key Linear Congruential Generator (LCG)," dalam KOMIK (Konferensi Nasional Teknologi Informasi dan Komputer), 2017.

[12] K. B. Boateng dan A. H. Lashkari, "Securing GOOSE : The Return of One-Time Pads," dalam International Carnahan Conference on Security Technology (ICCST), Chennai, 2019.

[13] N. Khairina, M. K. Harahap, A. M. Husein, Muhathir dan R. Muliono, "Secure Data Encryption Through Combination of RSA Cryptography Random Key Algorithm and Quadratic Congruential Generator," dalam Journal of Physics: Conference Series, 2019.

[14] R. Aulia, A. Zakir dan M. Zulhafiz, "Penerapan Algoritma One Time Pad \& Linear Congruential Generator Untuk Keamanan Pesan Teks,” InfoTekJar : Jurnal Nasional Informatika dan Teknologi Jaringan, vol. 4, no. 1, 2019.

[15] Sugiyono, Metode Penelitian Kuantitatif, Kualitatif, dan Kombinasi, Bandung: Alfa Beta, 2012.

[16] J. E. kaufmann dan K. L. Schwitters, Algebra for college students., Cengage Learning, 2014.

[17] I. M. D. Biantara, I. M. Sudana, A. F. Suni, Suyono dan A. Hangga, "Modifikasi Metode Linear Congruential Generator Untuk Optimalisasi Hasil Acak.," dalam Seminar Nasional Informatika (SEMNASIF), Yogyakarta, 2015.

[18] E. H. Rachmawanto dan C. A. Sari, "Secure image steganography algorithm based on det with otp encryption.," Journal of Applied Intelligent System, vol. II, no. 1, pp. 1-11, 2017.

[19] O. Tornea, M. E. Borda, V. Pileczki dan R. Malutan, "DNA Vernam cipher."," dalam E-Health and Bioengineering Conference (EHB), 2011.

[20] C. A. Sari dan E. H. Rachmawanto, "Gabungan Algoritma Vernam Chiper dan End of File Untuk Keamanan Data.," Jurnal Teknologi Informasi, vol. XIII, no. 3, pp. 150-157, 2014. 
JURNAL MEDIA INFORMATIKA BUDIDARMA

Volume 4, Nomor 3, Juli 2020, Page 841-849

ISSN 2614-5278 (media cetak), ISSN 2548-8368 (media online)

Available Online at https://ejurnal.stmik-budidarma.ac.id/index.php/mib

DOI 10.30865/mib.v4i3.2244

[21] R. Shukla, H. O. Prakash, R. P. Bhushan, S. Venkataraman dan G. Varadan, "Sampurna Suraksha: unconditionally secure and authenticated one time pad cryptosystem.," dalam International Conference on Machine Intelligence and Research Advancement, India, 2013.

[22] D. R. I. M. Setiadi, E. H. Rachmawanto dan C. A. Sari, "Implementasi One Time Pad Kriptografi Pada Gambar Grayscale Dan Gambar Berwarna.," dalam Proceeding SENDI U, Semarang, 2017.

[23] R. Chang, Kimia Dasar : Konsep - Konsep Inti, Jakarta: Erlangga, 2005. 